\title{
Course of Income Inequality in Turkey
}

\author{
Fazıl Kayıkçı \\ Department of Economics, Yıldız Technical University, İstanbul, Turkey \\ Email: fkayikci@yildiz.edu.tr
}

How to cite this paper: Kayikçi, F. (2019) Course of Income Inequality in Turkey. Theoretical Economics Letters, 9, 2085-2092. https://doi.org/10.4236/tel.2019.96131

Received: July 18, 2019

Accepted: August 26, 2019

Published: August 29, 2019

Copyright $\odot 2019$ by author(s) and Scientific Research Publishing Inc. This work is licensed under the Creative Commons Attribution International License (CC BY 4.0).

http://creativecommons.org/licenses/by/4.0/

\begin{abstract}
The simultaneous treatment of growth, inequality and poverty is useful from a policy perspective in the sense that it enables decision makers to choose the combination of mutually beneficial policies that have positive impact on all three variables. Also, public policies tend to affect inequality mainly indirectly through their impact on growth and poverty. Turkey, as being one of the developing countries, has high-income inequality since its Gini coefficient was around 0.40 in last decades according to Turkish Statistical Institute. Its income distribution has been improving slightly; however, it is still so much behind the developed countries' levels. Inequalities in the wealth distribution can have significant negative impacts on growth where credit market constraints prevent the poor from making productive indivisible investments. This can be overcome by the provision of credit or redistribution of assets by taxes and other interventions. Redistribution of assets not only causes to increase growth and reduce inequality, but also reduces the poverty directly by insuring the poor against the macroeconomic shocks or volatilities.
\end{abstract}

\section{Keywords}

Poverty, Inequality, Income Distribution, Growth, Development

\section{Introduction}

The distribution of income within a country is important for several reasons. Inequalities may create incentives for people to improve their situation through work, innovation or acquiring new skills. On the other hand, it may be an obstacle to growth and reducing poverty. Also, crime and social exclusion are often seen as linked to inequalities of income distribution. Most economists would agree that some inequality is essential to a market economy [1]. Inequality is necessary to provide rewards to those who invest in their skills as well as to those who take risk and responsibility [2]. In addition, any attempt at redistribution must be judged against its effects on essential economic incentives that allocate 
talent and resources. However, [3] conclude that inequality can indeed be detrimental for growth when it is coupled with imperfect credit markets and unequal access to education. The authors argue that inequalities can result in inefficiently low levels of physical and human capital investment, and lower aggregate productivity and growth.

Turkey is experiencing a considerable economic growth and low inflation with macroeconomic stability in last decades after many years of economic crisis and macroeconomic imbalances. Whereas in the last decades the primary concern was the inflation targeting or debt reducing economic programs, then the distribution of income emerges as an important issue for the policymakers. When we analyze the current situation of inequality in Turkey, we see high level of income inequality, which is closer to that seen in the most unequal countries of Latin America and Sub-Saharan Africa. It is also unfortunately far from the typical range observed among European Union countries. Nevertheless, it is important to note that over the last years inequality has declined in Turkey, while it has risen in many countries.

This paper is organized as follows: in the next section, the theoretical relationship between inequality, poverty and growth is analyzed with examples from the literature. In the third section, some definitions about the inequality measurements are given. In the fourth section, the current situation of inequality in Turkey is briefly presented with comparisons of past years and other countries besides arguing about the reasons for inequality. The fifth section suggests some policy recommendations to decrease inequality.

\section{Interdependency of Inequality, Growth and Poverty}

Inequality is simultaneously determined with other variables in the process such as growth and poverty. In order to analyze the impact of public policy on income distribution, the modeling framework that accounts for the simultaneity in the determination of poverty, inequality and growth should be used. As pointed out by [4], accounting for the simultaneity of the above variables allows first to avoid the shortcomings of previous studies that deal with each variable separately. Second, the simultaneous treatment of growth, inequality and poverty is useful from a policy perspective in the sense that it enables decision makers to choose the combination of mutually beneficial and mutually exclusive policies that have positive impact on all three variables. Third, public policies tend to affect inequality mainly indirectly through their impact on growth and poverty. The simultaneous treatment of growth, income distribution and poverty that model explicitly the interaction between all the variables involved is, therefore, the most appropriate tool to assess the direct as well as the indirect channels through which public policies affect inequality [5].

[6] points out that "change in the distribution of income can be decomposed into two effects, a proportional change in all incomes that leaves the distribution of relative income unchanged (a growth effect) and a change in the distribution of relative incomes, which, by definition, is independent of the mean (a distribu- 
tional effect). Specifically; the growth and the inequality elasticity of poverty are increasing functions of the level of development and decreasing functions of the degree of relative income inequality" [6]. This can be seen from Figure 1, where the poverty headcount is simply the area under the density curve at the left of the poverty line (here set at US\$1 a day). This figure shows the density of the distribution of income that is the number of individuals at each level of income represented on a logarithmic scale on the horizontal axis. The move from the initial to the new distribution goes through an intermediate step, which is the horizontal translation of the initial density curve to curve (I). Then, moving from curve (I) to the new distribution curve occurs at constant mean income. This movement thus corresponds to the change in the distribution of "relative" income, or the "distribution" effect. This view is dominant today, which was empirically worked so much by many economists, and [7] were the first to point out that initial inequality seemed to be empirically associated with lower growth rates. The figure shows clearly that both growth and inequality changes play a major role in generating changes in poverty. However, the impact of them depends on not only the initial level of income and inequality but also the differences across countries.

There is a widely accepted view that economic growth in low-income countries will deteriorate the equity, and this view has had considerable influence on thinking about development policy; "the rich are usually the first to reap the benefits of national income growth" [8]. [9], by claiming that inequality will increase in the early stages of growth in a developing country and then, after some point, it will begin to fall, defines the relationship between inequality and average income on the plane as an inverted U. [9] centered his argument on the impact of rural to urban migration flows on the distribution of incomes during the development process. The idea is that "even if within-sector inequality is constant and the ratio of mean sectoral incomes is also constant, the shift of population

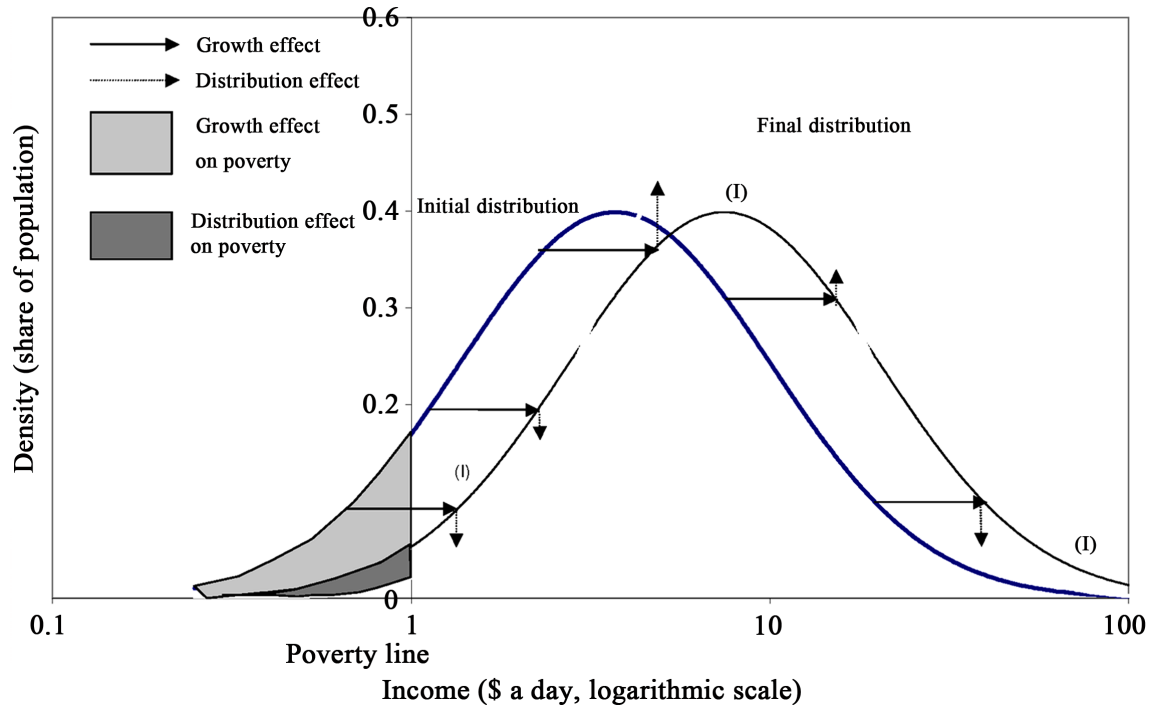

Figure 1. Decomposition of poverty into growth and distributional effects [6]. 
between sectors at first produces a widening in inequality and then a narrowing" [10]. While Kuznets [9] used a numerical example, [10] provided a more rigorous proof of Kuznets' hypothesis and his demonstration was based on the existence of intersectoral difference in mean income and did not require a higher average income or a greater level of inequality in the growing sector. According to this hypothesis, growth is account for more reduction in the poverty rate at the middle-income levels since that level associated with decreasing inequality. Thus, the effects of even the same development policies differ according to initial inequality and the income level of the country they are implemented in.

\section{Measures of Income Inequality}

Low income and consumption, and inequality in their distribution, are the key determinants of the wellbeing of the population. One of the common indicators of inequality is the decile $90 / 10$. In this analysis, the decile $90 / 10$ is the adjusted per adult equivalent deflated consumption of the 90th percentile divided by per adult equivalent deflated consumption of the 10th percentile, that is, the consumption of the poorest person in the richest decile over the consumption of the richest person in the first or poorest decile. This indicator is easy to interpret, but it does not reflect the situation in the middle of the distribution [11].

Another common inequality measure is the Gini coefficient, which is sensitive to all the parts of distribution. The Gini coefficient is a measure of statistical dispersion most prominently used as a measure of inequality of income distribution. It is bounded between 0 and 1; it is 0 in the case of absolute equality, when the per equivalent consumption of each person is the same, and it is 1 in the case of absolute inequality, when one person consumes everything and others consume nothing. The Gini coefficient is defined as a ratio of the areas on the Lorenz curve. If the Lorenz curve is represented by the function $Y=L(X)$, the Gini coefficient can be calculated as:

$$
G=1-2 \int_{0}^{1} L(x) \mathrm{d} x
$$

\section{Income Inequality in Turkey}

Turkey, as being one of the developing countries, has high-income inequality since its Gini coefficient was 0.42 according to Household Budget Survey of 2003 which is conducted by the Turkish Statistical Institute. Its income distribution has been improving at last decades; however, it is still so much behind the developed countries' levels. Below, in Table 1, we can see the change in the distribution of income both through the decrease of the value of the Gini coefficient and the increase (decrease) of the income share of the lowest and middle income (highest) group. Table 2 shows the distribution of income in the same period using the ratio of average income by each quintile with respect to the average income of the lowest quintile. In both tables, income represents the total annual household income. 
Table 1. Distribution of income in turkey.

\begin{tabular}{ccccccccc}
\hline Quintiles & 1968 & 1973 & 1986 & 1994 & 2002 & 2003 & 2009 & 2017 \\
\hline Lowest 20\% & 3.0 & 3.5 & 3.9 & 4.86 & 5.3 & 6.0 & 5.6 & 6.3 \\
Next 20\% & 7.0 & 8.0 & 8.4 & 8.63 & 9.8 & 10.3 & 10.3 & 10.7 \\
Next 20\% & 10.0 & 12.5 & 12.60 & 12.91 & 14.0 & 14.5 & 15.1 & 14.8 \\
Next 20\% & 20.0 & 19.5 & 19.20 & 19.03 & 20.8 & 20.9 & 21.5 & 20.9 \\
Highest 20\% & 60.0 & 56.5 & 55.9 & 54.88 & 50.1 & 48.3 & 47.6 & 47.4 \\
Gini Coefficient & 0.56 & 0.51 & 0.46 & 0.49 & 0.44 & 0.42 & 0.41 & 0.40 \\
\hline
\end{tabular}

a. Source: [12] and author calculations from Turkish statistical institute database.

Table 2. International comparisons, distribution of household per capita income.

\begin{tabular}{ccccccccc}
\hline Quintiles & $\begin{array}{c}\text { Latin } \\
\text { America and } \\
\text { Caribbean }\end{array}$ & $\begin{array}{c}\text { Sub } \\
\text { Saharan } \\
\text { Africa }\end{array}$ & $\begin{array}{c}\text { East Asia } \\
\text { and Pacific }\end{array}$ & $\begin{array}{c}\text { South } \\
\text { Asia }\end{array}$ & $\begin{array}{c}\text { Eastern } \\
\text { Europe }\end{array}$ & $\begin{array}{c}\text { Middle } \\
\text { East and } \\
\text { North Africa }\end{array}$ & $\begin{array}{c}\text { Developed } \\
\text { Countries }\end{array}$ & Turkey \\
\hline 1 and 2 & 13.2 & 14.1 & 18.1 & 21.7 & 22.2 & 17.8 & 18.4 & 15.1 \\
3 and 4 & 33.8 & 33.5 & 37.5 & 38.4 & 40.0 & 39.8 & 41.8 & 34.8 \\
5 & 52.9 & 52.4 & 44.3 & 39.9 & 37.8 & 45.4 & 39.8 & 50.1 \\
\hline
\end{tabular}

This table very clearly illustrates current income inequality in Turkey. The numbers in Table 1 also show that Turkey has had high-income inequality for decades. Since 1963, income share of the households in the lowest income quintile has been about $3 \%$ to $6 \%$, while the share of the top quintile has been at least about $48 \%$ or higher. Yet, the distribution of household income improved significantly between 1963 and 1987. Except the increase in 1994 because of the crisis, Gini coefficient declined from 0.56 in 1968 to 0.40 in 2017.

These differences are all the more significant if we correct our income measure to capture differences in household sizes, and use annual per-capita household income. The richer households do not only have more resources but also they share it among a smaller number of household members. Another exercise is analyzing the extreme ends of the distribution. An analysis at the percentile level shows that the annual average per-capita incomes of the richest $1 \%$ of households were 250 times more than the poorest $1 \%$ in 2002: average annual income of the richest $1 \%$ of households was about $\$ 52,000$ compared to $\$ 240$ of the lowest $1 \%$ [13].

To place Turkey in a broader context, Table 2 presents similar statistics from other countries. It shows per-capita income distribution in Turkey and different parts of the World. In only two regions, Latin America and Sub-Saharan Africa, the distribution of per capita income is more unequal than Turkey. A closer look at the income shares in Turkey and in a more equal region, such as within developed countries, also shows that the main difference is the larger share of income received by the top $20 \%$. Of course, if the top $20 \%$ is getting a larger share in Turkey than they do in developed countries, some other groups must be get- 
ting less. Surprisingly, it is the middle-income group (households in the 3rd and 4 th income quintiles) that gets a lower share, $41.8 \%$ versus $34.8 \%$. The income share of the bottom $40 \%$ is quite close at $18.4 \%$ versus $15.1 \%$.

When we think about the reasons for income inequality, we can be faced with several reasons. First, people are born with different initial conditions. Some are raised in richer families with the necessary resources to invest in their children's education. Others are born in poorer families with only limited means. Similarly, some have parents with high human capital and can therefore benefit from their formal education and their connections, while others may not be so fortunate. Second, institutions, such as the education system, play an important role. If high-quality education were freely available to all children, family background would not play such an important role. On the other hand, if educational opportunities are limited by individuals' economic or social background, education can in fact worsen the differences in initial conditions rather than reducing them. In the figure below, we can see the effect of education on the income level. Adding to the above argument about the effect of family size on the inequality, we can mention about the education as a primary cause of inequality.

\section{Conclusions}

Turkey, as being one of the developing countries, has high-income inequality since its Gini coefficient was around 0.40 in last decades according to Turkish Statistical Institute. Its income distribution has been improving slightly; however, it is still so much behind the developed countries' levels. Inequalities in the wealth distribution can have significant negative impacts on growth where credit market constraints prevent the poor from making productive indivisible investments. Turkey is experiencing a considerable economic growth and low inflation with macroeconomic stability in last decades after many years of economic crisis and macroeconomic imbalances.

We analyzed the theoretical relationship between inequality, poverty and growth and defined growth, defined the inequality measurements from the literature. After stating the current situation of inequality in Turkey with comparisons of past years and other countries besides arguing about the reasons for inequality, now we argue about some policy implications.

\section{Policy Implications}

The policy implication for reducing inequality, such as providing a wide access to education and health will benefit the poor both through directly and through indirectly by stimulating growth. [14] showed that policies mandating compulsory schooling, financed by a proportional tax on wage income, increase economic growth and, by distributing from agents with high human capital endowment to those with the less, make the intergenerational distribution of income more equal. Moreover, there is a strong evidence that changes in income inequality are related to investment in human capital and thus to borrowing 
constraints. As argued by [15], the worsening in income inequality observed in Latin America in recent years appears to have been the result of growing inequalities in educational opportunities and inadequate access to credit markets.

Inequalities in the wealth distribution can have significant negative impacts on growth where credit market constraints prevent the poor from making productive indivisible investments. This can be overcome by the provision of credit or redistribution of assets by taxes and other interventions. Also, political structure plays a central role in the redistribution decisions. The poor can able to make profitable investment project by the expansion of credit market and this may accelerate growth process. And if the negative relationship is realized after some level of income as in the Kuznets Hypothesis, and the economy enters into the cycle of higher growth and decreasing inequality forever. Redistribution of assets not only causes to increase growth and reduce inequality, but also reduces the poverty directly by insuring the poor against the macroeconomic shocks or volatilities.

\section{Conflicts of Interest}

The authors declare no conflicts of interest regarding the publication of this paper.

\section{References}

[1] Stiglitz, J. (2012) The Price of Inequality: How Today's Divided Society Endangers Our Future. 2nd Edition, W.W. Norton \& Company, New York.

[2] Schumpeter, J. (1934) The Theory of Economic Development. Harvard Economic Studies, Cambridge MA.

[3] Aghion, P., Caroli, E. and García-Peñalosa, C. (1999) Inequality and Economic Growth: The Perspective of the New Growth Theories. Journal of Economic Literature, 37, 1615-1660. https://doi.org/10.1257/jel.37.4.1615

[4] Lundberg, M. and Lyn, S. (1999) The Simultaneous Evolution of Growth and Inequality. The Economic Journal, 113, 326-344.

https://doi.org/10.1111/1468-0297.00127

[5] Laabas, B. and Limam, I. (2004) Impact of Public Policies on Poverty, Income Distribution and Growth. Arab Planning Institute Working Paper Series, No. 0401, Kuwait.

[6] Bourguignon, F. (2003) The Growth Elasticity of Poverty Reduction: Explaining Heterogeneity across Countries and Time Periods. In: Eicher, T. and Turnovsky, S., Eds., Inequality and Growth. Theory and Policy Implications, The MIT Press, Cambridge, MA.

[7] Alesina, A. and Rodrik, D. (1994) Distributive Politics and Economic Growth. The Quarterly Journal of Economics, 109, 465-490. https://doi.org/10.2307/2118470

[8] Watkins, K. (1995) The OXFAM Poverty Report. OXFAM, Oxford. https://doi.org/10.3362/9780855988128

[9] Kuznets, S. (1955) Economic Growth and Income Inequality. The American Economic Review, 45, 1-28.

[10] Adelman, I. and Robinson, S. (1989) Income Distribution and Development. In: 
Chenery, H. and Srinivasan, T., Eds., Handbook of Development Economics, Elsevier Science Oublishers, Amsterdam, 949-1003.

[11] Joint Poverty Assessment Report (2005) Volume 1 and 2. Document of the State Institute of Statistics, Turkey and World Bank.

[12] Yükseler, Z. and Türkan, E. (2007) Türkiye'de Hanehalkı: Gelir, Harcamave Yoksulluk Açısından Analizi. Turkish Economic Association Discussion Paper, No. $2007 / 4$.

[13] Duygan, B. and Güner, N. (2006) Income and Consumption Inequality in Turkey: What Role Does Education Play? In: Altuğ, S. and Filiztekin, A., Eds., The Turkish Economy: The Real Economy, Corporate Governance and Reform and Stabilization Policy, Routledge, London, 63-91.

[14] Eckstein, Z. and Zilcha, I. (1994) The Effects of Compulsory Schooling on Growth İncome Distribution and Welfare. Journal of Public Economics, 54, 339-359. https://doi.org/10.1016/0047-2727(94)90040-X

[15] Londono, J.L. and Szekely, M. (1997) Distributional Surprises aftera Decade of Reforms: Latin America in the Nineties, Working Paper No. 352, Inter-American Development Bank. 